Assessing the Effect of a Combined Malaria Prevention Education and Free Insecticide-Treated Bed Nets Program on Self-Reported Malaria Among Children in a Conflict-Affected Setting in Northern Uganda

Robert Ssengonzi and Frederick Makumbi

April 2010 
About the Authors

Robert Ssengonzi, PhD, is a senior research health specialist at RTI

International.

Frederick Makumbi, PhD, is a senior lecturer at Makerere University, School of Public Health.
RTI Press publication RR-0010-1004

This PDF document was made available from www.rti.org as a public service of RTI International. More information about RTI Press can be found at http://www.rti.org/rtipress.

RTI International is an independent, nonprofit research organization dedicated to improving the human condition by turning knowledge into practice. The RTI Press mission is to disseminate information about RTI research, analytic tools, and technical expertise to a national and international audience. RTI Press publications are peer-reviewed by at least two independent substantive experts and one or more Press editors.

\section{Suggested Citation}

Ssengonzi, R., and Makumbi, F. (2010). Assessing the Effect of a Combined Malaria Prevention Education and Free Insecticide-Treated Bed Nets Program on Self-Reported Malaria Among Children in a Conflict-Affected Setting in Northern Uganda. RTI Press publication No. RR-0011-1004. Research Triangle Park, NC: RTI International. Retrieved [date] from http://www.rti.org/rtipress.
This publication is part of the RTI Press Research Report series.

RTI International

3040 Cornwallis Road

PO Box 12194

Research Triangle Park, NC

27709-2194 USA

Tel: $\quad+1.919 .541 .6000$

Fax: $\quad+1.919 .541 .5985$

E-mail:_rtipress@rti.org

Web site: www.rti.org
(C)2010 Research Triangle Institute. RTI International is a trade name of Research Triangle Institute.

All rights reserved. Please note that this document is copyrighted and credit must be provided to the authors and source of the document when you quote from it. You must not sell the document or make a profit from reproducing it.

doi:10.3768/rtipress.2010.rr.0010.1004

www.rti.org/rtipress 


\title{
Assessing the Effect of a Combined Malaria Prevention Education and Free Insecticide-Treated Bed Nets Program on Self-Reported Malaria Among Children in a Conflict-Affected Setting in Northern Uganda
}

\begin{tabular}{lr} 
Contents & \\
Introduction and Background & 2 \\
Data and Methods & 2 \\
$\quad$ Study Area & 2 \\
Program Design & 4 \\
Sampling and Data Collection & 4 \\
\multicolumn{1}{c}{ Data Analysis } & 5 \\
Results & 6 \\
Discussion & 8 \\
References & 11 \\
Acknowledgments Inside back cover
\end{tabular}

\author{
Robert Ssengonzi and Frederick Makumbi
}

\begin{abstract}
We examine whether a concerted malaria prevention education effort is associated with reduced malaria disease burden among children under the age of 5 years residing in conflict-affected settings in Northern Uganda. Two camps for internally displaced persons were identified in the Lira District of Northern Uganda. All residents in both camps were given free insecticide treated nets (ITNs), along with basic information on installation and use. In one camp, Ogur, an intense malaria prevention education intervention through community meetings, household visits, and posters was administered to camp residents for a 6-month period by trained community health care workers who were also camp residents. The residents of Ogur camp also received assistance in hanging their ITNs as needed from the resident community health workers. In the other camp, Abia, no additional health education intervention was provided after the ITN distribution. After 6 months, a survey was conducted among a cross-section of respondents from each camp. The results from this survey show significantly lower rates of reported malaria among children under 5 years in the intervention camp (Ogur) compared with children in the reference camp (adj. $R R=0.68$; $95 \%$ Cl: 0.50, 0.91). This suggests that including enhanced malaria prevention education as an integral component of ITN distribution programs could help promote the use of malaria prevention methods and help stem malaria infections.
\end{abstract}




\section{Introduction and Background}

Malaria is the leading cause of morbidity and mortality among children under 5 years of age (U5) in Uganda. According to the Uganda Ministry of Health $(\mathrm{MOH})$, Plasmodium falciparum malaria is endemic in 95 percent of the country $(\mathrm{MOH}, 2006)$, with nearly 50 percent of the population experiencing high transmission levels of 50 or more infective mosquito bites per person per year. Proper and consistent use of insecticide treated nets (ITNs) can reduce malaria episodes by as much as 50 percent (Lengeler, 2004). Further, because of their cost-effectiveness as compared with other malaria control interventions, use of ITNs is highly recommended to reduce the incidence of malaria (Choi, Breman, Teutsch, Luo, Hightower, \& Sexton, 1995; Wiseman, Hawley, ter Kuile, Phillips-Howard, Vulule, Nahlen, et al, 2003; World Health Organization, 2005).

Despite the increasing coverage of ITNs in Uganda, availability and ownership is still low. About 26 percent of households in the nation own at least one ITN, but significant disparities exist between urban and rural residents (MOH and ORC Macro, 2006). One key constraint to net ownership in Uganda, as in other parts of the sub-Saharan region, is limited affordability (Kachur, Phillips-Howard, Odhacha, Ruebush, Oloo, \& Nahlen, 1999; Nuwaha, 2001). In the case of Northern Uganda, the 20-year internal conflict has decimated the living conditions and economic viability of the residents, leading to their increased vulnerability to malaria and other illnesses.

Increased availability of ITNs, accompanied by concerted health promotion and education campaigns, does improve net usage (Dike, Onwujekwe, Ojukwu, Ikeme, Uzochukwu, \& Shu, 2006; Rhee, Sissoko, Perry, McFarland, Parsonnet, \& Doumbo, 2005; Lin, Aung, Lwin, Min, Aye, \& Webber, 2003; Minja, Schellenberg, Mukasa, Nathan, Abdulla, Mponda, et al., 2001). However, few studies have looked at the effect of enhanced health education on bed net utilization and malaria disease burden in a highly endemic setting after controlling for availability of nets, especially among the most vulnerable children, those below 5 years of age. In this paper, we examine whether enhanced malaria health education provided by trained community health workers through various mechanisms including peer training, community mobilizations, and home visits led to a higher rate of net utilization and a reduced malaria disease burden among vulnerable children U5 in Northern Uganda. This intervention is compared with a situation in which ITNs were issued without enhanced health education.

\section{Data and Methods}

\section{Study Area}

We assessed a program intervention conducted among residents of two camps for internally displaced persons in Ogur and Abia, in Lira District, Northern Uganda, between December 2005 and July 2006. The two camps were among those least served with malaria prevention and control programs in Lira district and had very low rates of ITN ownership (see baseline data in Table 1). They were about 10 kilometers apart, sharing similar climate, geographical, and environmental characteristics. We selected these camps in collaboration with the district health authorities so as to increase coverage of the ITNs to the residents there. At the time of program implementation, both camps had been in place for more than 3 years and were occupied by residents from nearby villages who had been displaced from their homes as a result of internal conflict in the region and a lack of security. Residents in both camps depended on support from government and aid agencies for subsistence.

Baseline data collected from both camps at the beginning of the program show that the attributes of respondents in both camps are comparable (see Table 1). However, Ogur camp was significantly larger than Abia camp, and more respondents in Ogur than in Abia reported owning ITNs and having received malaria education in the past 6 months. Mobility was restricted to daytime before dark in both camps, so potential outside exposure to malaria infection during travel, especially in the evening, was comparable as well. It is worth noting, however, that although restricted travel may have helped to limit contamination between the two camps, we did not consider contamination as part of the study design, as this program was not set up as a full clinical trial. 
Table 1. Characteristics of respondents and households by camp at baseline

\begin{tabular}{|c|c|c|c|c|c|}
\hline \multirow[b]{2}{*}{ Characteristics } & \multicolumn{2}{|c|}{ Ogur-Intervention } & \multicolumn{2}{|c|}{ Abia-Reference } & \multirow{2}{*}{$\begin{array}{c}\text { Fisher's exact } \\
p \text {-value }\end{array}$} \\
\hline & Number & Percentage & Number & Percentage & \\
\hline Total ${ }^{a}$ & $171^{b}$ & 100 & $163^{b}$ & 100 & \\
\hline \multicolumn{6}{|l|}{ Sex } \\
\hline Female & 77 & 45.0 & 61 & 37.4 & 0.182 \\
\hline Male & 94 & 55.0 & 102 & 62.6 & \\
\hline \multicolumn{6}{|l|}{ Age } \\
\hline $14-29$ & 67 & 39.6 & 48 & 30.2 & \\
\hline $30-49$ & 80 & 47.3 & 66 & 41.5 & 0.006 \\
\hline $50-83$ & 16 & 9.5 & 30 & 18.9 & \\
\hline Unknown & 6 & 3.6 & 15 & 9.4 & \\
\hline \multicolumn{6}{|l|}{ Education level } \\
\hline None & 36 & 21.1 & 45 & 27.4 & \\
\hline Some primary & 77 & 45.0 & 68 & 41.5 & 0.398 \\
\hline Post-primary & 58 & 33.9 & 51 & 31.1 & \\
\hline Marital status & 171 & & 157 & & \\
\hline Married & 161 & 94.2 & 148 & 94.3 & 1.000 \\
\hline Not married & 10 & 5.8 & 9 & 5.7 & \\
\hline Relation to household head & 170 & & 163 & & \\
\hline Head & 73 & 42.9 & 80 & 49.1 & \\
\hline Spouse & 85 & 50.0 & 74 & 45.4 & 0.517 \\
\hline Other & 12 & 7.1 & 9 & 5.5 & \\
\hline \multicolumn{6}{|l|}{ Duration spent in the camp, in years } \\
\hline $0-1$ & 47 & 27.5 & 46 & 28.2 & 0.903 \\
\hline $2+$ & 124 & 72.5 & 117 & 71.8 & \\
\hline \multicolumn{6}{|l|}{ Last time had malaria education } \\
\hline Within last 6 months & 69 & 44.23 & 46 & 30.87 & \\
\hline No education or more than 6 months ago & 87 & 55.77 & 103 & 69.13 & 0.018 \\
\hline \multicolumn{6}{|l|}{ Source of education about malaria } \\
\hline None & 77 & 47.2 & 93 & 58.5 & \\
\hline NGOs & 33 & 20.2 & 29 & 18.2 & 0.104 \\
\hline Other & 53 & 32.5 & 37 & 23.3 & \\
\hline \multicolumn{6}{|l|}{ Best malaria prevention method } \\
\hline Net use & 96 & 78.7 & 95 & 76.0 & 0.650 \\
\hline Others & 26 & 21.3 & 30 & 24.0 & \\
\hline \multicolumn{6}{|l|}{ Total bed nets owned in household } \\
\hline 0 & 151 & 89.9 & 158 & 98.8 & \\
\hline 1 & 11 & 6.5 & 2 & 1.3 & 0.001 \\
\hline $2+$ & 6 & 3.6 & & & \\
\hline
\end{tabular}

$\mathrm{NGO}=$ nongovernmental organization.

a The number of cases on some variables does not add up to the total sample.

b The sample size of respondents interviewed at baseline is slightly different from that of respondents interviewed at follow-up. 
Lira district experiences two major rainfall seasons, in the months of March to May and September to November, each followed by a hot and dry period. According to district health authorities, malaria contributes the highest morbidity burden for U5 children. However, in the clinics/health centers accessible to camp residents, malaria is detected through passive case detection and a substantial proportion of the population does not seek treatment in the established health facilities.

\section{Program Design}

As part of program design, Ogur camp, with an estimated population of 26,000 , was assigned as the intervention arm. In addition to the general education on installation and use provided at the time of net distribution, community health workers (CHWs) - who were also residents of the campcontinuously administered a malaria education intervention program through community meetings, home visits, and peer education over a period of 6 months. Each CHW was responsible for a block of 80 to 120 households.

The CHWs were trained in skills of community mobilization and equipped with basic knowledge on malaria, its transmission patterns, and its prevention methods. Every 4 weeks, the CHWs conducted prevention education through block-level community meetings, targeting household members of the block that the $\mathrm{CHW}$ was in charge of. Project staff provided each $\mathrm{CHW}$ with a simple reference handbook on malaria prevention and control, which was in their local language, along with posters to use for illustration during education exercises. During the meetings, the CHWs taught household members about various aspects of malaria control and prevention, with an emphasis on the need for proper and consistent use of ITNs. Although the CHWs mobilized the residents to attend, actual attendance at the meetings was voluntary and not all adult household members attended. Thus, while some residents attended all six meetings, others attended fewer, and some did not attend at all.

In addition, the CHWs were responsible for training camp residents on other public health issues, including water and sanitation, and they conducted regular household visits to educate the residents about the various health issues. When CHWs visited residents' homes as part of their other responsibilities in the camps, they were instructed to ask household members about their experiences in the use of the ITNs and to provide assistance to residents who had challenges or problems with hanging the nets.

Abia camp, with an estimated 15,000 people, was assigned as the reference camp. The main difference is that in Abia, project staff provided residents with just one session of general education on installation and use of the ITNs, as the nets were distributed in January 2006. No CHWs trained in malaria prevention education lived in Abia during this period, no one conducted monthly follow-up community meetings on malaria prevention education, and household residents did not receive additional instruction or support in hanging or using their nets. The nets distributed in both camps, PermaNet 2.0, were long-lasting ITNs, as recommended by the WHO Pesticide Evaluation Scheme (WHOPES), retaining insecticidal activity for up to 20 washes (WHO, 2004).

\section{Sampling and Data Collection}

Our analysis for this research report is limited to 202 households that reported having at least one child U5 and also owning at least one bed net. These data were collected as part of a larger random sample survey conducted in the two camps in July 2006, 6 months after commencement of the ITN and education program as part of overall program monitoring and evaluation. This report uses data collected at post-intervention. Only one adult respondent was interviewed in each selected household after seeking informed consent. Female and male respondents were selected alternately in the sampled households.

Instruments with structured questions on a number of topics, including the respondent's sociodemographic information; the respondent's and other household members' knowledge, attitudes, and practice of malaria prevention and control methods; sleeping arrangements of household residents; and level of ITN ownership in the household were used in this assessment. All study instruments were reviewed by the primary author's institutional review board (IRB) and by the Ugandan $\mathrm{MOH}$, Lira District Directorate of Health Services, for ethical 
research compliance and for technical content and cultural appropriateness. The study instruments, initially developed by the authors in English, were translated into Luo (the local language spoken by respondents) and pilot-tested prior to their use in the field by the project staff. For quality control purposes, a consultant who was not part of the interview team independently reviewed the translation of all instruments to ensure that the intended meaning of each question was captured. Interviews were conducted by a team of researchers who were fluent in Luo and who were familiar with the geographical area where the study was conducted. Before starting the study, the research staff underwent intensive training sessions to enhance their skills in conducting interviews and to get a thorough orientation of the study instruments and ethical issues related to protection of human subjects.

\section{Data Analysis}

Statistical analysis was done using Stata Statistical Software version 9.2 (StataCorp, 2007). Our main outcome variable was the proportion of households with self-reported malaria among U5 children-hereafter referred to as household U5 malaria. Although it has challenges of misdiagnosis, self-reported malaria is an established proxy for measuring the burden of malaria disease burden, especially in settings such as this where the capacity to conduct laboratory diagnoses for malaria is limited (see, for instance, Mbonye, Bygbjerg, \& Magnussen, 2008; Sumba, Wong, Kanzaria, Johnson, \& John, 2008). Household U5 malaria was calculated as the number of respondents who reported having had cases of malaria in their households among U5 children during the past 6 months, divided by the total number of all households with U5 children.

In this analysis, the study arms-intervention (Ogur) and reference (Abia) - are the primary comparison groups. Other covariates assessed were those perceived as risk factors for malaria infection. These included the following:

- Level of knowledge and use of effective malaria prevention methods. Awareness of the causes of malaria and ways of avoiding infection vary, and education programs are one avenue to improving understanding of the disease as a means of prevention (Baume \& Marin, 2008; Hlongwana et al., 2009). Varying levels of malaria prevention education provided in the two camps is expected to differentially influence self-reported malaria in the two camps.

- Ownership and use of bed nets. Both ownership and use of nets are included as independent variables, as ownership alone is insufficient for prevention (Baume \& Marin, 2007).

- Sleeping arrangements for adults and children in the household (whether children sleep with parents, by themselves, or with other children). Previous studies have shown that children are most likely to use a net if they share a bed with their mother (Baume \& Marin, 2007; Mugisha \& Arinaitwe, 2003).

- Duration of sickness for malaria episodes.

- Respondent perception of the severity of malaria in the study community. Some studies have shown that use of ITNs is likely to increase at times when malaria is perceived as being particularly severe, as demonstrated by documented seasonal use in several countries (Eisele et al., 2009; Prakash et al., 2008), in spite of the fact that transmission risks can remain high even when there is low vector density (Baume \& Marin, 2007).

We estimated the prevalence risk ratio of household U5 malaria by comparing categories of each covariate, instead of the odds ratio, which would have overestimated the risk ratio given that our sample had reported prevalence of household U5 malaria of more than 10 percent, making it a nonrare event (Greenland, 1987). In the crude analysis, we estimated crude risk ratios with 95 percent confidence intervals (95\% CI) using log-binomial models (Guangyong, 2004). In the adjusted analysis, we included in the final model all covariates with $p$-value $<0.15$ and potential confounders. We also tested for the interaction between variables and dropped them if they were not found to be statistically significant at the 5 percent level. 


\section{Results}

Table 2 shows household and respondents' characteristics by study arm 6 months after the distribution of bed nets. The difference in respondents' characteristics, including age, sex, and education level, was not statistically significant. However, respondents in the treatment arm were more than twice as likely to have received education on malaria control and prevention in the past 6 months
(79.6 percent vs. 33.6 percent, $p<0.001$ ). Additional analysis (data not shown in the table) show that of the respondents who reported having received education on malaria control and prevention, the majority in the intervention arm reported having received malaria education within 1 to 3 months before the interview, and a small proportion of the reference camp reported having received malaria education -66.0 percent in the intervention camp vs. 24.7 percent in the reference camp $(p<0.001)$. This may suggest that

Table 2. Characteristics of respondents and households at 6-month follow-up, by camp

\begin{tabular}{|c|c|c|c|c|c|}
\hline \multirow[b]{2}{*}{ Characteristics } & \multicolumn{2}{|c|}{ Ogur-Intervention } & \multicolumn{2}{|c|}{ Abia-Reference } & \multirow{2}{*}{$\begin{array}{c}\text { Fisher's exac } \\
p \text {-value }\end{array}$} \\
\hline & Number & Percentage & Number & Percentage & \\
\hline Overalla & $103^{b}$ & 100.0 & $99^{b}$ & 100.0 & \\
\hline \multicolumn{6}{|l|}{ Respondents' Characteristics } \\
\hline \multicolumn{6}{|l|}{ Sex } \\
\hline Female & 58 & 56.3 & 46 & 46.5 & \\
\hline Male & 45 & 43.7 & 53 & 53.5 & 0.205 \\
\hline \multicolumn{6}{|l|}{ Age group } \\
\hline $14-29$ & 56 & 54.9 & 40 & 40.4 & \\
\hline $30-49$ & 33 & 32.4 & 46 & 46.5 & \\
\hline $50-83$ & 11 & 10.8 & 11 & 11.1 & \\
\hline Unknown & 2 & 2.0 & 2 & 2.0 & 0.172 \\
\hline \multicolumn{6}{|c|}{ Relationship to head of household } \\
\hline Head & 43 & 41.8 & 52 & 52.5 & \\
\hline Spouse & 52 & 50.5 & 42 & 42.4 & \\
\hline Other & 8 & 7.8 & 5 & 5.1 & 0.269 \\
\hline \multicolumn{6}{|l|}{ Education level } \\
\hline None & 34 & 33.3 & 30 & 30.3 & \\
\hline Some primary (1-6 years) & 37 & 36.3 & 45 & 45.5 & \\
\hline Primary or higher (7+ years) & 31 & 30.4 & 24 & 24.2 & 0.401 \\
\hline \multicolumn{6}{|c|}{ Whether respondent received malaria education in past 6 months } \\
\hline No & 21 & 20.4 & 65 & 66.3 & \\
\hline Yes & 82 & 79.6 & 33 & 33.6 & $<0.001$ \\
\hline \multicolumn{6}{|c|}{ Single most effective malaria prevention method known } \\
\hline Sleeping under a bed net & 94 & 91.3 & 74 & 74.8 & 0.002 \\
\hline Other & 9 & 8.7 & 25 & 25.3 & \\
\hline \multicolumn{6}{|l|}{ Duration lived in camp (years) } \\
\hline $0-1$ & 3 & 2.9 & 13 & 13.1 & \\
\hline $2+$ & 99 & 97.1 & 86 & 86.9 & 0.009 \\
\hline
\end{tabular}


Table 2. Characteristics of respondents and households at 6-month follow-up, by camp (continued)

\begin{tabular}{|c|c|c|c|c|c|}
\hline \multirow[b]{2}{*}{ Characteristics } & \multicolumn{2}{|c|}{ Ogur-Intervention } & \multicolumn{2}{|c|}{ Abia-Reference } & \multirow{2}{*}{$\begin{array}{c}\text { Fisher's exact } \\
p \text {-value }\end{array}$} \\
\hline & Number & Percentage & Number & Percentage & \\
\hline Overalla & $103^{b}$ & 100.0 & $99^{b}$ & 100.0 & \\
\hline \multicolumn{6}{|l|}{ Household characteristics } \\
\hline \multicolumn{6}{|l|}{ Had U5 malaria in past 6 months } \\
\hline No & 64 & 62.1 & 45 & 45.5 & \\
\hline Yes & 39 & 37.9 & 54 & 54.6 & 0.024 \\
\hline \multicolumn{6}{|c|}{ Severity of malaria in households with U5 malaria case } \\
\hline No U5 malaria reported & 64 & 62.1 & 45 & 45.9 & \\
\hline Not severe & 20 & 19.4 & 8 & 8.2 & $<0.001$ \\
\hline Severe & 19 & 18.5 & 45 & 45.9 & \\
\hline \multicolumn{6}{|l|}{ Number of sleeping units/spaces } \\
\hline $1-2$ & 86 & 83.5 & 82 & 82.8 & \\
\hline $3+$ & 17 & 16.5 & 17 & 17.2 & 1.000 \\
\hline $\begin{array}{l}\text { Mean number of sleeping spaces in } \\
\text { household }\end{array}$ & $1.9(0.9)$ & - & $1.8(0.8)$ & - & 0.8428 \\
\hline $\begin{array}{l}\text { Mean number of regular persons } \\
\text { sleeping in household }\end{array}$ & $6.4(2.7)$ & - & $6.1(2.2)$ & - & 0.3800 \\
\hline \multicolumn{6}{|l|}{ Person per sleeping space } \\
\hline $1-2$ & 13 & 12.6 & 12 & 12.1 & \\
\hline$>2-4$ & 62 & 60.2 & 64 & 64.7 & \\
\hline$>4$ & 28 & 27.2 & 23 & 23.3 & 0.801 \\
\hline \multicolumn{6}{|l|}{ U5 sleeping arrangements } \\
\hline Other means & 16 & 16.2 & 19 & 19.8 & \\
\hline With parents & 83 & 83.8 & 77 & 80.2 & 0.577 \\
\hline \multicolumn{6}{|c|}{ Known malaria prevention methods currently used in household } \\
\hline None/ineffective methods & 27 & 26.2 & 40 & 40.4 & \\
\hline Effective methods & 76 & 73.8 & 59 & 59.6 & 0.037 \\
\hline
\end{tabular}

$-=$ Percentages not applicable.

a The number of cases on some variables does not add up to the total sample.

b The sample size of respondents interviewed at baseline is slightly different from that of respondents interviewed at follow-up. 
some of the respondents in the reference camp may have reported as education the guidance on ITN use they received as they received the nets. Similarly, a significantly higher proportion of respondents in the intervention camp compared with the reference camp were likely to mention bed nets as the single most effective malaria prevention method (91.3 percent vs. 74.8 percent, $p=0.002$ ).

These findings underscore the impact of the concerted education efforts in the treatment arm compared to the reference camp. Yet it is notable that even with a concerted education effort by the CHWs in the treatment arm, a sizable proportion of respondents had not been reached. On the other hand, the proportion of respondents who had lived in the camps for less than 1 year is higher in the reference camp compared to the treatment camp (13 percent vs. 3 percent), and it is not clear whether they might have received some malaria education before they moved to the reference camp.

At the household level, comparable findings were observed in the proportion of households with children U5 and in the sleeping arrangements of the household members (number of sleeping units in households and persons per sleeping space). The proportion of households reporting malaria among children U5 was significantly lower in the intervention arm (37.9 percent vs. 54.6 percent, $p=$ 0.024 ), as was the proportion reporting severe malaria in their households during the past 6 months (18.5 percent vs. 45.9 percent, $p<0.0001)$. A significantly higher proportion of respondents in the intervention arm reported current use of any effective malaria prevention methods (use of any bed net, insecticide sprays, or coils) in their household compared with respondents in the reference camp (73.8 percent vs. 59.6 percent, $p=0.037$ ).

Table 3 shows the crude and adjusted risk ratios (RR) of household U5 malaria. In the crude analysis, the risk of households experiencing U5 malaria was significantly lower in the intervention arm (RR $=0.69 ; 95 \%$ CI: $0.51,0.94)$. Factors significantly associated with lower risk of malaria included household reported use of effective malaria prevention methods ( $\mathrm{RR}=0.72$; 95\% CI: 0.54, 0.96), knowledge of challenges of bed nets $(\mathrm{RR}=0.68 ; 95 \%$
CI: 0.47, 0.99), and respondents' perception of the extent of malaria in their community as "very bad" $(\mathrm{RR}=0.64 ; 95 \% \mathrm{CI}: 0.47,0.86)$. On the other hand, households with children U5 who were reported as sleeping with their parents most of the time had an increased risk of reporting U5 malaria, although this association was not statistically significant $(R R=1.44$; 95\% CI: 0.89, 2.4).

In the adjusted analysis, reduced reporting of household U5 malaria was still significantly associated with being in the treatment camp (adj. RR $=0.68$; 95\% CI: 0.50, 0.91); current use of an effective malaria prevention method (adj. $\mathrm{RR}=0.75$; $95 \% \mathrm{CI}$ : $0.56,0.99)$; awareness of challenges with bed nets (adj. RR $=0.63$; 95\% CI:0.44 0.90); and respondents' opinions of the extent of malaria problem as being "very bad" in their communities (adj. RR $=0.64$; $95 \%$ CI: $0.48,0.85$ ). The proportion of households with children U5 using bed nets the night before an interview was also associated with a reduced risk of reporting household U5 malaria if 100 percent of the children U5 used bed nets, but this was not statistically significant (adj. RR $=0.76 ; 95 \% \mathrm{CI}: 0.57$, 1.05). However, as in the crude analysis, households with children U5 who were reported as sleeping with their parents most of the time had an increased risk of household U5 malaria, although it was not statistically significant (adj. RR $=1.51 ; 95 \%$ CI: 0.94, 2.45).

\section{Discussion}

This study indicates a significantly lower reported burden of self-reported U5 malaria in households with children U5 in the treatment arm, where distribution of free insecticide-treated bed nets was combined with health education, compared with households with children U5 in the reference camp, to whom free bed nets were distributed but who received no continued education after the instruction provided during the distribution process. The significant association of a reduction in reported household U5 malaria with the proper use of malaria prevention methods and better knowledge of the challenges of malaria appears to underscore the effect of a more concerted prevention education campaign in increasing the uptake of prevention methods, 
Table 3. Number, proportion, and crude and adjusted risk ratios of households reporting malaria in children under 5 years of age (U5) in the past 6 months

\begin{tabular}{|c|c|c|c|c|c|}
\hline \multirow[b]{2}{*}{ Characteristics } & \multicolumn{3}{|c|}{ Households } & \multirow[b]{2}{*}{$\begin{array}{c}\text { Crude } \\
\text { Risk Ratio (95\% CI) }\end{array}$} & \multirow[b]{2}{*}{$\begin{array}{c}\text { Adjusted } \\
\text { Risk Ratio } \\
(95 \% \mathrm{Cl})\end{array}$} \\
\hline & Total Numbe & $\begin{array}{l}\text { Reporting } \\
\text { U5 Malaria }\end{array}$ & $\begin{array}{c}\text { Proportion } \\
\text { Reporting } \\
\text { U5 Malaria (\%) }\end{array}$ & & \\
\hline Overalla & 202 & 93 & 46.0 & & \\
\hline \multicolumn{6}{|l|}{ Treatment arm } \\
\hline Ogur-Intervention & 103 & 39 & 37.9 & $0.69(0.51,0.94)$ & $0.68(0.50,0.91)$ \\
\hline Abia-Reference & 99 & 54 & 54.5 & 1.0 & 1.0 \\
\hline \multicolumn{6}{|c|}{ Malaria prevention methods currently used in household } \\
\hline None/Ineffective methods & 67 & 38 & 56.7 & 1.0 & 1.0 \\
\hline Effective methods & 135 & 55 & 40.7 & $0.72(0.54,0.96)$ & $0.75(0.56,0.99)$ \\
\hline \multicolumn{6}{|c|}{ Proportion of U5 using bed nets previous night } \\
\hline$<100$ percent & 67 & 35 & 52.2 & 1.0 & 1.0 \\
\hline 100 percent & 135 & 58 & 43.0 & $0.82(0.61,1.11)$ & $0.78(0.57,1.05)$ \\
\hline \multicolumn{6}{|c|}{ Frequency of bed net washing (number of times) } \\
\hline $1-2$ & 65 & 30 & 46.2 & $1.10(0.69,1.73)$ & \\
\hline $3-4$ & 80 & 38 & 47.5 & $1.13(0.73,1.75)$ & \\
\hline $5+$ & 38 & 16 & 42.1 & 1.0 & \\
\hline \multicolumn{6}{|l|}{ Any known bed nets challenges? } \\
\hline No & 139 & 71 & 51.1 & 1.0 & 1.0 \\
\hline Yes & 63 & 22 & 34.9 & $0.68(0.47,0.99)$ & $0.63(\mathbf{0 . 4 4}, \mathbf{0 . 9 0})$ \\
\hline \multicolumn{6}{|c|}{ Duration have had bed nets (months) } \\
\hline $1-6$ & 135 & 62 & 45.9 & 1.0 & \\
\hline $7+$ & 40 & 18 & 45.0 & $0.98(0.66,1.45)$ & \\
\hline \multicolumn{6}{|l|}{ U5 sleeping arrangements } \\
\hline Not with parents & 35 & 12 & 34.3 & 1.0 & 1.0 \\
\hline With parents most of the time & 160 & 79 & 49.4 & $1.44(0.89,2.4)$ & $1.51(0.94,2.45)$ \\
\hline \multicolumn{6}{|c|}{ Number of correct malaria signs and symptoms named } \\
\hline $1-2$ & 81 & 35 & 43.2 & 1.0 & \\
\hline At least 3 & 113 & 52 & 46.0 & $1.06(0.77,1.47)$ & \\
\hline \multicolumn{6}{|c|}{ Known death due to malaria in past 6 months } \\
\hline No & 63 & 32 & 50.8 & 1.0 & \\
\hline Yes & 139 & 61 & 43.9 & $0.86(0.63,1.18)$ & \\
\hline \multicolumn{6}{|c|}{ Perceived extent of the malaria problem } \\
\hline Bad/Not so much & 35 & 23 & 65.7 & 1.0 & \\
\hline Very bad & 167 & 70 & 41.9 & $0.64(0.47,0.86)$ & $0.64(0.48,0.85)$ \\
\hline \multicolumn{6}{|c|}{ Whether respondent had malaria education in past 6 months } \\
\hline No & 86 & 40 & 46.5 & 1.0 & \\
\hline Yes & 115 & 53 & 46.1 & $0.99(0.73,1.34)$ & \\
\hline
\end{tabular}

$\mathrm{Cl}=$ confidence interval; U5 = children under age 5 .

a The number of cases on some variables does not add up to the total sample. 
as has been observed elsewhere. In addition, respondents who knew of challenges in using ITNs reported lower household U5 malaria, perhaps an indication that knowledge of the challenges arose from more experience in using the nets and that in doing so, the respondents were also able to address the challenges faced and thereby benefit from the protection of the ITNs.

Households with respondents who reported that the severity of the malaria problem in their camp was "very bad" had a significantly lower prevalence of U5 malaria-a 36 percent lower risk. Similarly, households with respondents who reported knowledge of a death related to malaria in the past 6 months had a 14 percent reduced risk of household U5 malaria. Indeed, households with respondents who either perceived malaria to be "very bad" in their camps or who knew of a malaria-related death in the past 6 months had a significantly reduced risk of household U5 malaria (adj. RR $=0.61 ; 95 \%$ CI: 0.42 , $0.90)$. This observed reduction in risk of household U5 malaria may have been due to increased utilization of malaria prevention methods motivated by respondents' perceptions.

The data indicate that when 100 percent of children U5 used an ITN, as measured by the children who were reported to have slept under a bed net the previous night, the reported risk of household U5 malaria fell by 22 percent. This result suggests that in order to significantly reduce the household burden of U5 malaria, it is important that all children under the age of 5 use protective measures.

Some potential limitations of this study are worth discussing. First, it can be argued that the health education intervention may have influenced people's awareness and perceptions of malaria, influencing their responses about household U5 malaria at follow-up, whether or not there was a change in malaria incidence. This could affect the responses in the two camps in counteracting ways. In Ogur camp, where $\mathrm{CHWs}$ provided enhanced malaria education, increased knowledge about malaria control and prevention could lead to better and more correct identification of malaria symptoms among children than in Abia camp, where no enhanced malaria education was provided. Second, we did not collect data on reported household U5 malaria prevalence at baseline, which would have enabled us to more appropriately assess the changes in self-reported malaria prevalence that could be attributed to our intervention. Therefore, observed differences could in part be due to pre-existing differences in household U5 malaria in the two communities. Finally, the study was conducted in only one treatment and one reference camp. Thus, some of the observed differences might pertain to the unique heterogeneity of these two camps, which could have averaged out had the study been conducted in multiple camps. It is important to consider these factors when interpreting the results in this research report.

In conclusion, this study endeavors to highlight the additional contribution of concerted malaria prevention education to the proper use of malaria prevention methods and to reduced burden of household U5 malaria in endemic settings. The magnitude of the difference in the effect of enhanced malaria prevention education on bed net use and reduced malaria disease burden, when compared to just having access to the methods with limited or no continuing education, could be even greater over time. Incidentally, we were not able to assess this magnitude, as the camp residents were resettled 10 months after commencement of the program as the security in the region improved. It is also notable that using trained community health workers from within the community to conduct the intensive health education requires fewer resources, thereby increasing the prospects for a sustainable intervention. We recommend that programs engaged in the control and prevention of malaria-and especially those using ITNs-consider providing enhanced health education as an integral component of their activities. We also recommend studies to examine the optimal intervals of follow-up education efforts after the distribution of nets. 


\section{References}

Baume, C., \& Marin, M. C. (2008). Gains in awareness, ownership and use of insecticide-treated nets in Nigeria, Senegal, Uganda and Zambia. Malaria Journal, 7(1), 153-163.

Baume, C., \& Marin, M. (2007). Intra-household mosquito net use in Ethiopia, Ghana, Mali, Nigeria, Senegal, and Zambia: Are nets being used? Who in the household uses them? American Journal of Tropical Medicine and Hygiene, 77(5), 963-971.

Choi, H. W., Breman, J., Teutsch, S. M., Luo, S., Hightower, A. W., \& Sexton, J. D. (1995). The effectiveness of insecticide-impregnated bed nets in reducing cases of malaria infection: A metaanalysis of published results. American Journal of Tropical Medicine and Hygiene, 52, 377-382.

Dike, N., Onwujekwe, O., Ojukwu, J., Ikeme, A., Uzochukwu, B., \& Shu, E. (2006). Influence of education and knowledge on perceptions and practice to control malaria in Southeast Nigeria. Social Science \& Medicine, 63, 103-106.

Eisele, T., Keating, J., Littrell, M., Larsen, D., \& Macintyre, K. (2009). Assessment of insecticidetreated bednet use among children and pregnant women across 15 countries using standardized national surveys. American Journal of Tropical Medicine and Hygiene, 80(2), 209-214.

Greenland, S. (1987). Interpretation and choice of effect measures in epidemiological analysis. American Journal of Epidemiology, 125, 761-768.

Guangyong, Z. (2004). A modified Poisson regression approach to prospective studies with binary data. American Journal of Epidemiology, 159, 702-706.

Hlongwana, K., Mabaso, M., Kunene, S., Govender, D., \& Maharaj, R. (2009). Community knowledge, attitudes and practices (KAP) on malaria in Swaziland: A country earmarked for malaria elimination. Malaria Journal, 8, 29-37.

Kachur, S., Phillips-Howard, P., Odhacha, A., Ruebush, T., Oloo, A., \& Nahlen, B. (1999). Maintenance and sustained use of insecticidetreated bed-nets and curtains three years after a controlled trial in Western Kenya. Tropical Medicine \& International Health, 4, 728-735.
Lengeler, C., 2004. Insecticide-treated bed nets and curtains for preventing malaria. Cochrane Database Systems Review no. 2, p. CD000363.

Lin, K., Aung, S., Lwin, S., Min, H., Aye, N. N., \& Webber, R. (2003). Promotion of insecticidetreated mosquito nets in Myanmar. Southeast Asian Journal of Tropical Medicine and Public Health, 31, 444-447.

Mbonye, A., Bygbjerg, I., \& Magnussen, P. (2008). Prevention and treatment practices and implications for malaria control in Mukono District Uganda. Journal of Biosocial Science, 40(2), 283-296.

Minja, H., Schellenberg, J. A., Mukasa, O., Nathan, R., Abdulla, S., Mponda, H., ... Obrist, B. (2001). Introducing insecticide-treated nets in the Kilombero Valley, Tanzania: The relevance of local knowledge and practice for an information, education and communication (IEC) program. Tropical Medicine \& International Health, 6 , 614-623.

Ministry of Health (MOH), Uganda. (2006). The burden of malaria in Uganda. Why all should join hands in the fight against malaria. www.health .go.ug/malaria.htm

Ministry of Health (MOH), Uganda and ORC Macro. (2006). Uganda HIV/AIDS Sero-Behavioural Survey, 2004-05. Calverton, Maryland, USA: Uganda Ministry of Health and ORC Macro.

Mugisha, F. \& Arinaitwe, J. (2003). Sleeping arrangements and mosquito net use among underfives: Results from the Uganda Demographic and Health Survey. Malaria Journal, 2(1), 40-50.

Nuwaha, F. (2001). Factors influencing the use of bed nets in Mbarara municipality of Uganda. American Journal of Tropical Medicine and Hygiene, 65, 877-882.

Prakash, A., Bhattacharyya, D., Mohapatra, P., Goswami, B., \& Mahanta, J. (2008). Community practices of using bed nets $\&$ acceptance $\&$ prospects of scaling up insecticide treated nets in north-east India. India Journal of Medical Research, 128(5), 623-629. 
Rhee, M., Sissoko, M., Perry, S., McFarland, W., Parsonnet, J., \& Doumbo, O. (2005). Use of insecticide-treated nets (ITNs) following a malaria education intervention in Piron, Mali: A control trial with systematic allocation of households. Malaria Journal, 4, 35.

StataCorp LP. (2007). Stata/SE statistical software, version 9.2. College Station, Texas, USA.

Sumba, P., Wong, S., Kanzaria, H., Johnson, K., \& John, C. (2008). Malaria treatment-seeking behaviour and recovery from malaria in a highland area of Kenya. Malaria Journal, 7, 245-253.

World Health Organization (WHO) and United Nations Children's Fund (UNICEF). (2005). World Malaria Report 2005. Roll Back Malaria Partnership. Geneva.
World Health Organization (WHO) Pesticides Evaluation Scheme (WHOPES) (2004). Fifth update on long lasting insecticidal nets: Current status and programmatic issues. Geneva. Retrieved December 19, 2006, from http://rbm.who.int/docs/ updateLLN_5.htm

Wiseman, V., Hawley, W. A., ter Kuile, F. O., PhillipsHoward, P. A., Vulule, J. M., Nahlen, B. L., \& Mills, A. J. (2003). The cost-effectiveness of permethrintreated bed nets in an area of intense malaria transmission in western Kenya. American Journal of Tropical Medicine and Hygiene, 68, 161-167. 


\section{Acknowledgments}

This study was supported by the U.S. Centers for Disease Control and Prevention under grant number U50/CCU425125-01. 
RTI International is an independent, nonprofit research organization dedicated to improving the human condition by turning knowledge into practice. RTI offers innovative research and technical solutions to governments and businesses worldwide in the areas of health and pharmaceuticals, education and training, surveys and statistics, advanced technology, international development, economic and social policy, energy and the environment, and laboratory and chemistry services.

The RTI Press complements traditional publication outlets by providing another way for RTI researchers to disseminate the knowledge they generate. This PDF document is offered as a public service of RTI International. More information about RTI Press can be found at www.rti.org/rtipress. 